\title{
Bird mortality from the Deepwater Horizon oil spill. II. Carcass sampling and exposure probability in the coastal Gulf of Mexico
}

\author{
J. Christopher Haney ${ }^{1,4, *}$, Harold J. Geiger ${ }^{2}$, Jeffrey W. Short ${ }^{3}$ \\ ${ }^{1}$ Terra Mar Applied Sciences LLC, 123 West Nye Lane, Suite 129, Carson City, Nevada 89706, USA \\ ${ }^{2}$ St. Hubert Research Group, 222 Seward, Suite 205, Juneau, Alaska 99801, USA \\ ${ }^{3}$ JWS Consulting LLC, 19315 Glacier Highway, Juneau, Alaska 99801, USA \\ ${ }^{4}$ Present address: Defenders of Wildlife, 1130 17th St. NW, Washington, DC 20036, USA
}

\begin{abstract}
Two separate approaches, a carcass sampling model and an exposure probability model, provided estimates of bird mortalities of 600000 and 800 000, respectively, from the 2010 Deepwater Horizon MC 252 oil spill in coastal waters of the Gulf of Mexico. Monte Carlo simulation of parameter uncertainty led to respective $95 \%$ uncertainty intervals of 320000 to 1200000 and 160000 to 1900000 . Carcass sampling relied on expansion factors multiplied by counts of bird carcasses retrieved in shoreline surveys, whereas exposure probability estimated bird deaths as a product of estimated coastal bird density, average oil slick size, slick duration, and proportionate mortality due to oiling. The low proportion of small-sized carcasses recovered, compared with considerably higher proportions of small live birds in coastal Gulf habitats, indicate an especially low probability of recovery for small birds after oil spills at sea. Most mortality affected 4 species: laughing gull Leucophaeus atricilla (32\% of the northern Gulf of Mexico population killed), royal tern Thalasseus maximus (15\%), northern gannet Morus bassanus (8\%) and brown pelican Pelecanus occidentalis $(12 \%)$. Declines in laughing gulls were confirmed by $\sim 60 \%$ reductions in National Audubon Society Christmas Bird Count data for 2010-2013 along the Gulf coast. Population-level effects in apex predators of this magnitude likely had effects on prey populations that warrant careful assessment.
\end{abstract}

KEY WORDS: Avian mortality $\cdot$ Exposure probability $\cdot$ Carcass sampling $\cdot$ Oil spill $\cdot$ Deepwater Horizon · Gulf of Mexico · Coastal habitat · Christmas Bird Count · Monte Carlo simulation

\section{INTRODUCTION}

Large oil spills into the coastal ocean can kill hundreds of thousands of birds (Piatt \& Ford 1996, Tan et al. 2008, Munilla et al. 2011). Petroleum exposure alters feather microstructure (Jenssen 1994, O'Hara \& Morandin 2010), compressing plumage so that it loses its buoyancy, insulating function, and flight capability (Leighton 1993). Physiological health of birds is further impaired by oil-induced diseases (Briggs et al. 1996), including hemolytic anemia,

\footnotetext{
*Corresponding author: chaney@defenders.org
}

ulcerations, cachexia, and aspergillosis (Balseiro et al. 2005). Birds contaminated at sea thereby die due to drowning, hypothermia, starvation, or dehydration.

The largest accidental release of petroleum into marine waters in history (Camilli et al. 2012, McNutt et al. 2012), the Deepwater Horizon MC 252 blowout was an unprecedented perturbation to the northern Gulf of Mexico. The cumulative slick area exceeded $100000 \mathrm{~km}^{2}$ (Norse \& Amos 2010, Garcia-Pineda et al. 2013). Oiling impacts extended from the pelagic ocean seaward of the continental slope, across the

(C) The authors 2014. Open Access under Creative Commons by Attribution Licence. Use, distribution and reproduction are unrestricted. Authors and original publication must be credited. 
continental shelf, and into remote brackish estuaries along the Gulf coastline (Peterson et al. 2012, Michel et al. 2013).

Avian mortality is one direct, immediate measure of ecological impact caused by a marine oil spill. Because it is impossible to observe each seabird death from acute oil exposure, total mortality is usually inferred from shoreline carcass surveys and probability-based expansion factors to account for birds that are killed but not collected (e.g. an Oiled Seabird Mortality Model; Wiese \& Robertson 2004). These factors account for birds that die but disappear before arriving on shore (Wiese 2003, Munilla et al. 2011) and those on shore that go undetected by spill responders (Van Pelt \& Piatt 1995, Byrd et al. 2009). Alternatively, seabird mortality can be estimated from the numbers of birds present and vulnerable to lethal exposure (Wilhelm et al. 2007, Haney et al. 2014, this volume).

Our objective here is to estimate coastal seabird mortality from acute oil exposure during the Deepwater Horizon spill. We compare mortality estimates derived from both a carcass sampling model and an exposure probability model. The carcass sampling model includes expansion factors for lost, missed, and unobservable bird carcasses. The exposure probability model is based on surveys of aerial seabird densities above coastal waters of the northern Gulf of Mexico, estimates of the size of the Deepwater Horizon oil slick, and an estimate of the proportion of oiled seabirds that subsequently died. The 2 approaches are based on largely independent data, providing an unusual opportunity to compare alternative models of estimating avian mortality after a large marine oil spill.

\section{MATERIALS AND METHODS}

\section{Study area and modeling domain}

Spatially, we limited the scope of investigation to coastal waters within $40 \mathrm{~km}$ offshore of the Gulf coast (see Fig. 1 in Haney et al. 2014), thus delineating an effective catchment area (sensu Wiese \& Robertson 2004). We chose $40 \mathrm{~km}$ as the likely maximum distance from shore inhabited routinely by coastal seabirds.

The Deepwater Horizon discharged oil into the Gulf from the day when the casing was breached on 20 April 2010 until the well was capped on 15 July 2010. Oil first appeared within $40 \mathrm{~km}$ of the coast on 28 April 2010. We thus considered the acute mortal- ity phase to last for 95 d, until 31 July 2010, to account for bird mortality from contact with lingering surface oil (Aeppli et al. 2012). Avian mortality clearly continued after the well was capped (based on wildlife collection reports) because the ratio of dead-to-live bird recoveries increased in late July 2010 (Belanger et al. 2010, Antonio et al. 2011).

\section{Bird carcass tallies by size category and location}

We obtained carcass counts retrieved in all habitats during the Deepwater Horizon incident and archived by spill response authorities (www.fws.gov/home/ dhoilspill/collectionreports.html, table dated 12 May 2011; accessed 22 March 2013). Using a total of 2121 carcasses identified as known oiled, we organized these counts by species and body size. Live moribund oiled birds were not counted as carcasses because they could reach shorelines independent of winds and currents (e.g. Stienen et al. 2004).

To account for variation in detectability with body size during spill response (Seys et al. 2001, Ford \& Zafonte 2009), each bird species and all individual birds were assigned to one of 3 size categories: large ( $\geq 500 \mathrm{~g})$, medium (300-499 g), or small (10-299 g). We excluded 92 bird carcasses not considered as coastal on the basis of primary habitat used by each species, life history traits, and migratory habits. Species of estuarine categorization included rails, gallinules, certain waders, and species that occur in terrestrial vegetation types.

Species that feed in the neritic zone and associated shorelines, including shorebirds and other seasonal migrants that rely upon beach or wide mudflats during the time of year of the spill, were broadly designated as coastal for purposes of oil exposure. Birds listed in the recovery archives as 'other' (a total of 31) and 'unknown' (a total of 51) were categorized as coastal and medium sized. Other birds tallied unknown to species were assigned to the same size category and habitat as the most commonly recovered species in that taxon (see Table S1 in the Supplement at www.int-res.com/articles/suppl/m513 p239_supp.pdf). Dead birds assigned to the coastal category but retrieved offshore (a total of 25 carcasses recovered before they reached shore; see www.fws.gov/home/dhoilspill/collectionreports.html), were also subtracted from the carcass tally. A total of 2004 bird carcasses constituted the observations that represented the recoveries of birds from the coastal habitat, comprising 128 small-, 1383 medium- and 493 large-bodied bird carcasses. 


\section{Carcass sampling model}

From a sampling perspective, carcass counts can be thought of as the realization of repeated stochastic sampling steps, with each step reducing the number of carcasses ultimately available for recovery (e.g. Seys et al. 2001, Wiese \& Robertson 2004). The unknown number of bird deaths in each body size category from the Deepwater Horizon spill was denoted as $N_{j}$, and the number of carcasses counted as $x_{j}$, with the index $j$ indicating body size category (1: large; 2: medium; 3: small). Within each body size category, a series of 5 stochastic steps reduced the carcasses available to be recovered by some proportion.

We denote $r$ as the probability that a carcass was transported and deposited on shore following a bird's death from oil, $l$ the probability that a carcass persisted on shore until it could be found, $h$ the proportion of habitat sampled for bird carcasses, $k$ the proportion of the total carcass deposition period systematically sampled with a fixed interval between successive sampling events, and $d$ the probability that a carcass would be detected by searchers. Parameters $r, l, h$, and $k$ were assumed to be the same for all bird body size categories. Parameter $d$ was assumed to vary by size category, with $d_{1}, d_{2}$, and $d_{3}$ the probabilities of detection that correspond to $x_{1}$, $x_{2}$, and $x_{3}$. For convenience, we let $p_{j}$ denote the combined probability that a bird from size category $j$ that died as a result of oil spill exposure was eventually recovered. Also, we used the caret notation to indicate between an estimate $\left(\mathrm{e} . \mathrm{g}, \hat{p}_{j}\right)$ of a parameter and we leave off the caret to denote either the true value or else the parameter as a random variable (in the Bayesian sense, e.g. $p_{j}$ ). Then, in a sampling context (Thompson 2002), the estimated number of total birds killed within size category $j$ is

$$
\hat{N}_{j}=\frac{x_{j}}{\hat{r} \hat{l} \hat{h} \hat{k} \hat{d}_{j}}=\frac{x_{j}}{\hat{p}_{j}}
$$

The grand total number of birds estimated killed is the sum of each $\hat{N}_{j}$.

Parameter selection

Carcasses adrift will vary in their final destination as a consequence of daily changes in wind speed and direction. Shelf currents in the northern and eastern Gulf of Mexico are dominated by wind and freshwater driven flows (Barker 2011). Surface oil reached Gulf shorelines only during strong onshore winds (MacFadyen et al. 2011). We therefore estimated car- cass drift from wind data, because neritic currents from the Mississippi and Atchafalaya River discharges are primarily alongshore to the west in response to Coriolis forcing.

The probability $r$ that a carcass was transported to shore depends on its initial position offshore, the carcass drift velocity towards a shoreline, and the probability of remaining afloat en route. We assumed the initial carcass position was proportional to the product of the relative area densities of seabirds and surface oil as a function of distance from shoreline, averaged over the $95 \mathrm{~d}$ when seabird carcasses were presumed present within $40 \mathrm{~km}$ of the shoreline. We assumed that coastal seabird density declined from a maximum at the shoreline to some negligibly low value $40 \mathrm{~km}$ offshore, proportional to $1-z / 40$, where $z$ indicates the distance from shoreline in $\mathrm{km}$. Daily oil slick size was calculated from shape files that were synthesized in the Experimental Marine Pollution Surveillance Daily Composite Products (www. ssd.noaa.gov/PS/MPS/deepwater.html; accessed 11 August 2013). Spatial depictions of the Deepwater Horizon oil slick in these products were based primarily on satellite sensors augmented with oil spill trajectory models and other ancillary data (see 'Parameter selection for exposure probability model' in the Supplement). The initial location of seabird carcasses was then assumed to be proportional to the product of the risk of oiling and the assumed seabird density of $1-z / 40$ (Table S2 in the Supplement).

We estimated shoreward carcass drift velocity from observations of wind velocities archived for Station BURL1, Southwest Pass, Louisiana, a C-MAN Station maintained by the National Data Buoy Center. We assumed a $2 \%$ coupling of wind and seabird carcass drift speeds (Seys et al. 2001, Castege et al. 2007), and a Coriolis deflection for seabird carcass drift of $18^{\circ}$ to the east (Poulain et al. 2009). Shorelines where seabird carcasses were deposited were assumed to face either southward (80\%) or eastward (20\%). Seabird carcass drift speeds were computed as the respective northward and westward components of the drift velocity vector, and the average values of these velocities $V_{\mathrm{N}}$ and $V_{\mathrm{W}}$ were determined. The overall average drift velocity, $\bar{V}$, of $4.1 \mathrm{~km} \mathrm{~d}^{-1}$ was computed as $\bar{V}=0.8 \bar{V}_{\mathrm{N}}+0.2 \bar{V}_{\mathrm{W}}$ (Table S3 in the Supplement).

We assumed carcasses lost buoyancy from decomposition at an instantaneous rate of $1.00 \mathrm{~d}^{-1}$ (see 'Computation of transport probability to shorelines' in the Supplement), based on results reported by Ford et al. (1991) and Wiese (2003) after accounting for temperature differences and for likely effects of 
scavengers that increase carcass decomposition rates. The probability that a carcass would remain afloat after a time $t$ at sea was computed as $\exp [-(1.00 t)]$, where $t=z / 4.1 \mathrm{~km} \mathrm{~d}^{-1}$. The probability $r$ that a carcass was transported to shore was computed as a numerical approximation of the integral of the product of this exponential function and the distribution of initial carcass positions at sea as described above (Table S4 in the Supplement).

Based on these assumptions regarding carcass losses at sea, $<1 \%$ of the carcasses would remain available for shoreline deposition after $4 \mathrm{~d}$. Integrating these time-dependent losses with the initial distribution of carcasses led to an estimated average proportion of carcasses reaching a shoreline of approximately $\hat{r}=$ 0.057 (Table S4). Most of this transport probability arises from carcasses within $15 \mathrm{~km}$ of the shore, beyond which the average transport time of $\sim 4 \mathrm{~d}$ or more leads to nearly complete removal of carcasses from the sea surface. The parameter $r$ was assigned a beta probability distribution with the mean centered at 0.057 to model uncertainty in this parameter.

To estimate the probability of carcass persistence on a beach prior to search and recovery, $l$, we assumed that a carcass survey was conducted every $3 \mathrm{~d}$, as was originally planned (USDOI 2011). We took the daily probability of carcass persistence to be 0.50 to account for removals by scavengers or burial by wind- or wave-driven sediment transport, a reasonable approximation based on other studies (Page et al. 1990, Seys et al. 2001). We assumed that the probability of a carcass persisting $n$ days was $0.50^{n}$ $(n \leq 3)$. Probability of carcass persistence, $l$, within this deposition interval was thus the average of $1 / 2$, $1 / 4$ and $1 / 8$, or 0.292 . We assigned this variable a beta distribution with a mean centered at 0.292 to model uncertainty.

We assumed that all Gulf shorelines exposed to neritic waters of the Gulf of Mexico and suitable for carcass deposition were searched, so $h=1.00$. We also assumed that $90 \%$ of the shoreline surveys for carcasses were separated by intervals of $3 \mathrm{~d}$ so $k=$ 0.90 . We assigned this variable a beta distribution with the mean centered at 0.90 to model uncertainty.

Estimates of searcher efficiency $\left(d_{j}\right)$ were based on Ford et al. (2013). We used a value of $0.424\left(=\hat{d}_{1}\right)$ as the estimate of searcher efficiency for large bird carcasses. Using the average of the 2 values for searcher efficiency reported in Table 2 from Ford et al. (2013) for small bird carcasses, we assumed $\hat{d}_{3}=0.078$. Finally, we assumed the average of the values for small and large bird carcasses, $\hat{d}_{2}=0.251$, as the searcher efficiency for medium-sized carcasses. These searcher efficiency parameters were also assigned beta distributions, with the means centered at the values listed above.

\section{Parameter uncertainty}

The beta probability distributions assigned to each unknown parameter represent our attempt to organize and display what we do and do not know about the parameter's location (Silver 2012), and to assess what would have happened had we used alternate assumptions about the parameter values. To explain how the variances of these distributions were derived, let $q$ represent any of the carcass model parameters. Because these are beta distributions for parameters, the associated distribution for $q$ has hyperparameters $a_{q}$ and $b_{q}$. The mean of the beta distribution is given by $a_{q} /\left(a_{q}+b_{q}\right)$ and the variance is also a function of $a_{q}$ and $b_{q}$ (Casella \& Berger 2002). We linked all of the beta distributions together, for all of the parameters, through a single common hyperparameter, $u$, such that $a_{q}=u \hat{q}$ and $b_{q}=u(1-\hat{q})$, for $\hat{q}$ representing the estimate of $r, l, k$, and each value of $d_{j}$. Without this step we would have had twelve individual hyperparameters to manipulate (2 hyperparameters for each beta distribution). Note that $u$ can be factored out of both numerator and denominator of the mean, so the mean is independent of $u$. However, the variance is strongly affected by $u$ : the larger the value of $u$, the smaller the variance of each parameter.

The value of hyperparameter $u$ was chosen so that distributions of all 6 model parameters were as consistent as possible with uncertainty in parameters described in the literature and with estimates from this and other oil spills (Table 1). Rather than develop even more complexity to express the uncertainty in $u$, we simply set the value of $u$ at 200 after acknowledging that the distribution of $N$ is sensitive to this choice. We established the value of $u$ at 200 by iterative fitting. That is, we varied $u$, examined the central $95 \%$ interval for each of the variables, and then readjusted $u$ until all 6 probability intervals closely approximated the $95 \%$ interval for parameter values that we considered plausible for likely alternate parameter assumptions (Table 1). Later, we doubled and halved this value of $u$ to assess the sensitivity of the analysis to our choice of $u$ (and to the assumed variance of the beta distributions, which $u$ controls).

After setting the value of $u$ at 200, we evaluated the overall uncertainty in our estimates by making re- 
peated random draws from the beta distributions of each carcass model parameter and then calculating $N_{j}$ and summing over $j$. The Monte Carlo distribution for $N$ was developed by taking 1 million random draws for each parameter $\left(r, l, h, k, d_{j}\right)$, then developing 1 million values of $N$ by the repeated use of Eq. (1) and summation over $j$.

\section{Exposure probability model}

Bird deaths from a spill can also be estimated using bird density $(D)$, the proportionate mortality due to oiling $(M)$, and the spatial extent of the oil (A). We assume that birds become contaminated with oil in direct proportion to the product of the spatial extent of oiling on the water and the density of seabirds within that spatial extent. The number of affected birds in contact with the oil multiplied by the proportionate mortality (bird deaths/oil-exposed bird) should then approximate $N$, the number of bird deaths, so $N=A D M$ (e.g. Wilhelm et al. 2007, Haney et al. 2014).

Estimating seabird mortality as the product of oil slick area, seabird density and proportionate mortality due to oiling presumes exposure population size equal to $A D$ for an exposure period sufficient to result in proportionate mortality $M$. This simple relation for estimating mortality due to oil exposure must be modified to account for exposure of new populations of birds owing to oil slick movement and to replacement of birds killed by oil exposure through immigration to the slick area, especially given the $\sim 3$ mo persistence of the Deepwater Horizon oil slick.

To account for the total population of birds exposed to oil, we introduce an effective exposure renewalperiod parameter, $P$, after which the population of birds exposed to oil is effectively renewed. Denoting the duration of the oil spill as $T$, there are $T / P$ such exposure renewal periods. If the area of the oil slick during the $i^{\text {th }}$ exposure renewal period is denoted as $A_{i}$, the number of birds killed during that period is $N_{i}=A_{i} D_{i} M_{i}$, where $D_{i}$ and $M_{i}$ are the bird density and proportionate mortality during that period. The total number of birds killed, $N$, is:

$$
N=\Sigma_{1}^{T / P} A_{i} D_{i} M_{i}
$$

If $D_{i}$ and $M_{i}$ are assumed constant over the duration of the oil spill $T$, it can readily be shown that $\Sigma_{1}^{T / p} A_{i}$ reduces to $\bar{A}(T / P)$, where $\bar{A}$ is the average oil slick area over the duration of the spill (Haney et al. 2014). Then the number of birds killed is simply:

$$
N=\bar{A} D M\left(\frac{T}{P}\right)
$$

\section{Parameter selection}

We set value of the period $P$ to $1 \mathrm{~d}$ based in part on information from satellite imagery for oil spill persistence and recurrence in coastal waters (see the Supplement for more detailed justifications of parameter values). We estimated the average extent of the surface oil slick $(\bar{A})$ as $3600 \mathrm{~km}^{2}$ for coastal waters of the northern Gulf of Mexico spill zone based on methods described above for the carcass sampling model. To simulate the uncertainty in $\bar{A}$, this parameter was treated as a random variable (in the Bayesian sense), and assigned a gamma distribution with shape parameter of 36 and a scale parameter of 100 (i.e. mean and standard deviation approx. 3600 and $600 \mathrm{~km}^{2} \mathrm{~d}^{-1}$, respectively). A gamma distribution was chosen because it has an inherent lower bound of zero but is otherwise similar to the normal distribution with the parameter values chosen. Two standard deviations constituted ca. $33 \%$ of the mean, which reflects uncertainty associated with the overestima- 
tion from pixel distortion and analyst misclassification during satellite image assessment for oil presence (e.g. Haney et al. 2014).

We assumed that the mean density of birds, $D$, was 5.8 birds $\mathrm{km}^{-2}$ based on McFarlane \& Lester (2005), who gave a range of 3.6 to 9.4 birds $\mathrm{km}^{-2}$. We assumed the density of seabirds in the coastal Gulf of Mexico remained at approximately this level because of several movement processes available for repopulating the spill zone. Birds in this area had flight speeds that facilitated influx to any part of the spill zone in less than $24 \mathrm{~h}$. Also, aerial foragers (species that use surface plunging, aerial dipping, aerial pursuit, skimming and hydroplaning; Nelson 1979) accounted for $96 \%$ of all species in the coastal seabird community in the Gulf, whereas more sedentary divers and other primarily surface foragers (a group mutually exclusive from aerial foragers, and that included loons, sea ducks, and phalaropes) are a negligible fraction (Johnson 2011). Finally, new birds arrived continuously into the region during the incident period via ongoing seasonal migrations. Seabird abundance in the Gulf of Mexico increases $17 \%$ from spring to summer (Peake 1996), and certain taxa (e.g. storm-petrels, shearwaters, and some terns) become 4 to 5 times more abundant (Hess \& Ribic 2000). This random variable $D$ was assigned a Poisson distribution (see Clarke et al. 2003, Oppel et al. 2012) with mean and variance of 5.8 birds $\mathrm{km}^{2}$ to reflect the observed range of seabird density in coastal waters (McFarlane \& Lester 2005).

We selected a value of 0.40 (i.e. $40 \%$ ) as an estimate of the proportionate mortality, $M$, in part based on the observed proportionate mortality in the oiled birds retrieved during the Deepwater Horizon (justification detailed in the Supplement). We also considered the proportionate mortality of aerial seabird species reported from other oil spills. Proportionate mortalities from $5 \%$ to near $90 \%$ from oil exposure are reported for marine birds, with rates of 22 to $89 \%$ (median 61\%) listed for 13 aerially foraging seabird groups (Camphuysen \& Heubeck 2001). This parameter was assigned a beta distribution with parameters $a=6$ and $b=9$ (mean of 0.40 and standard deviation of 0.12 ) so that most values in the distribution were below the median value of reported estimates noted above.

\section{Parameter uncertainty}

As in the carcass sampling approach, we used a Bayesian notion of probability to organize and weight plausible assumptions about alternative parameter values and to reflect our knowledge of parameter location based on available literature and observations from the Deepwater Horizon spill. A Monte Carlo distribution for the unknown number of bird deaths estimated by the exposure probability model was then developed by taking 1 million replicates from the distribution of the parameters (Table 1), then generating 1 million values using Eq. (3).

\section{RESULTS}

\section{Estimates of total bird deaths}

The carcass sampling and exposure probability approaches produced similar estimates for the number of bird deaths. Dividing the number of recovered carcasses by the estimated expansion factors (Table 2) gave an estimated 600000 bird deaths. Alternatively, assuming an average slick size of $3600 \mathrm{~km}^{2}$, a proportionate mortality of 0.40 bird deaths per exposed bird, and a bird density of 5.8 birds $\mathrm{km}^{-2}$, we estimated slightly over 8000 bird deaths $\mathrm{d}^{-1}$, on average. Expanding for all $95 \mathrm{~d}$ having an observed oil slick within $40 \mathrm{~km}$ of the coast, the number of bird deaths was estimated as approx. 800000 .

Notably, with the carcass sampling approach, expansion factors ranged from slightly under 200 to over 800 unobserved carcasses per each recovered carcass (Table 2), depending on size category. The largest expansion factor was for birds with small body sizes, the size category with the fewest number of carcasses found ( $6.4 \%$ of all recoveries). Numbers of bird deaths in the small body size category were ultimately estimated to be slightly over $15 \%$ of the total.

The Monte Carlo distribution of the number of bird deaths from carcass sampling had a mean of 630000 and a median of 590000 , indicating the distribution was skewed slightly toward larger values (Fig. 1). Approx. 95\% of the simulated probability covers the interval from 320000 to 1200000 bird deaths (shortest interval), whereas $80 \%$ of the simulated probability covers the interval from 390000 to 910000 . The probability that the number of bird deaths exceeded 400000 is approx. $89 \%$, and the probability that the number of bird deaths exceeded 500000 is approx. $69 \%$, based on the carcass sampling probability model.

The Monte Carlo distribution for the carcass sampling distribution of bird deaths was sensitive to the 
value of the hyperparameter $(u=200)$. A change to this hyperparameter changes the variances of all of the distributions of the parameters for the carcass survey together. Halving this hyperparameter to 100 increased the variance, flattened the distribution somewhat, and shifted the distribution toward larger values. This change raised the standard deviation of the $r$ parameter from 0.016 to 0.023 , the 1 parameter from 0.032 to 0.045 , and the $k$ parameter from 0.021 to 0.030 . The standard deviation of the Monte Carlo distribution of bird deaths increased from approx. 220000 to 400000 , the medians increased from 590000 to 620000 , and the upper $97.5^{\text {th }}$ percentile increased from 1.2 million to slightly over 1.8 million. Halving the hyperparameter again to 50 flattened the distribution of the total bird deaths even more, with the $97.5^{\text {th }}$ percentile being greater than 3 million bird deaths. In contrast, doubling $u$ to 400 reduced the standard deviation of the $r$ parameter from 0.016 to 0.012 , the 1 parameter from 0.032 to 0.023 , the $k$ parameter from 0.021 to 0.015 , and the $97.5^{\text {th }}$ percentile of the distribution to 920000 - values that we judged to be too small to reflect the actual uncertainty in the parameter values. We concluded that $u=$ 200 produced distributions of the parameters that were the most consistent with reasonable alternate assumptions about the parameter values.

The Monte Carlo distribution for the number of bird deaths using exposure probability was flatter, and centered over slightly higher values when compared to the distributions of estimates from the carcass sampling approach. The median of this distri-

Table 2. Estimates of the combined probability of final shoreline recovery for large-, medium-, and small-bodied seabirds (denoted $\hat{p}_{j}$ ) in a carcass-sampling model used to estimate mortality in coastal waters of the Gulf of Mexico during the Deepwater Horizon spill. The sampling-based expansion factor for the observed number of carcasses in the $i^{\text {th }}$ size category is the multiplicative inverse $\left(1 / \hat{p}_{j}\right)$ of the probability of recovery for each size class. $\hat{N}_{j}$ denotes a sampling-based estimate of the number of birds killed for body size $j$. Observed carcass counts were 493 for large birds $(j=1), 1383$ for medium birds $(j=2)$, and 128 for small birds $(j=3)$. All estimates are rounded (mortality estimates do not necessarily sum exactly due to rounding)

\begin{tabular}{|lccc|}
\hline Parameter & $\begin{array}{c}\text { Large birds } \\
(\geq 500 \mathrm{~g})\end{array}$ & $\begin{array}{c}\text { Medium birds } \\
(300-499 \mathrm{~g})\end{array}$ & $\begin{array}{c}\text { Small birds } \\
(10-299 \mathrm{~g})\end{array}$ \\
\hline$\hat{p}_{j}$ & 0.00635 & 0.00376 & 0.00117 \\
$1 / \hat{p}_{j}$ & 157 & 266 & 856 \\
$95 \%$ uncertainty \\
$\begin{array}{l}\text { interval for } 1 / \hat{p}_{j} \\
\hat{N}_{j}\end{array}$ & $90-330$ & $150-570$ & $440-2100$ \\
\hline
\end{tabular}

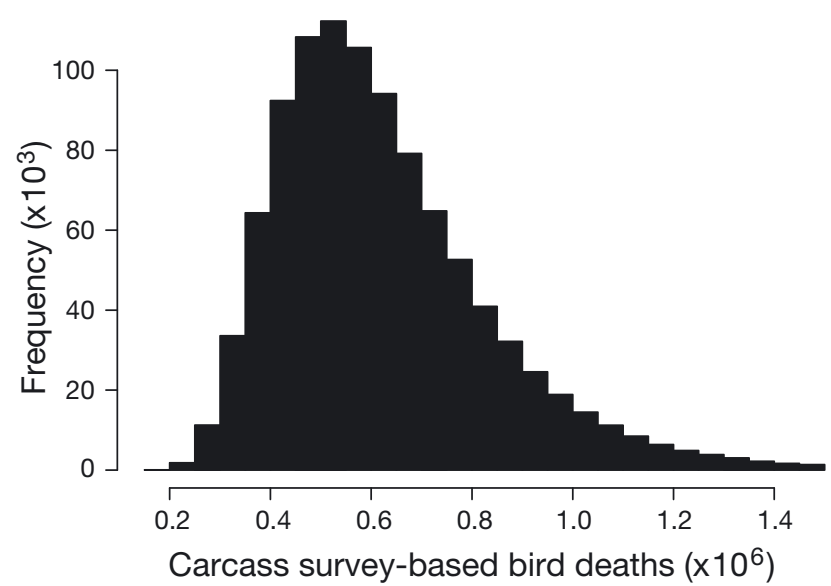

Fig. 1. Monte Carlo distribution (1 million simulation replicates) of the number of coastal bird deaths from the Deepwater Horizon oil spill based on a carcass survey approach to estimating total bird mortality. Median for the simulated distribution $=590000$ bird deaths; mean $=630000$

bution was approx. 700000 whereas the mean was approx. 800000, again skewed toward larger values (Fig. 2). The $95 \%$ uncertainty interval covers 160000 to 1900000 bird deaths, while the $80 \%$ interval covers 300000 to 1400000 . The probability that the number of bird deaths exceeded 400000 is approx. $81 \%$, and the probability that the bird deaths exceeded 500000 is approx. $72 \%$.

\section{Influence of carcass size}

Relative to their occurrence when surveyed while alive in coastal Gulf habitats, small-bodied carcasses were markedly under-represented in the tally of dead oiled birds found during the Deepwater Horizon spill (Fig. 3). As defined here, small-bodied birds account for about $34 \%$ of the communities in coastal habitats (Johnson 2011). Conversely, both mediumand large-bodied birds made up a disproportionately large proportion of the carcass counts relative to their occurrence in coastal habitat.

By implementing a searcher parameter $(d)$ specific to body size, the size distribution of bird-death estimates more closely matched the live proportions observed in the small-bodied bird category (Fig. 3). In addition, by using the size-group searcher efficiency parameters we eliminated entirely the disproportionately high representation of large-bodied birds in the carcass counts relative to their live occurrence in coastal Gulf habitats. However, the searcher efficiency adjustments did not reduce a similar discrepancy in representation seen for the medium size birds (Fig. 3). 


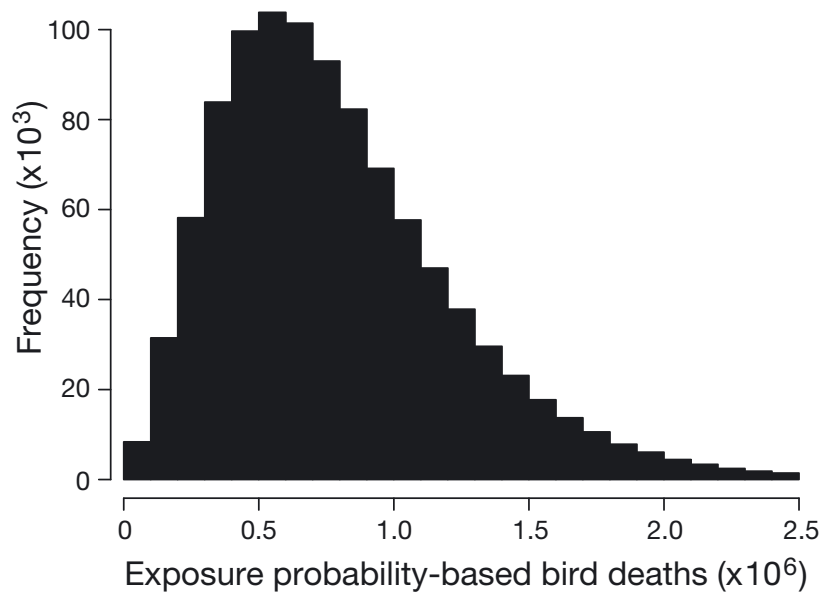

Fig. 2. Monte Carlo distribution (1 million simulation replicates) of the number of coastal bird deaths from the Deepwater Horizon oil spill based on an exposure probability model over $95 \mathrm{~d}$. Median number of bird deaths $\approx 700000$

\section{DISCUSSION}

Our results indicate that bird losses from the Deepwater Horizon oil spill almost certainly numbered into the hundreds of thousands in coastal waters of the northern Gulf of Mexico. Although each estimation approach was different conceptually — and used largely independent data - both showed that the most likely coastal bird mortality was approx. 700000 .

\section{Carcass sampling model}

Carcass sampling expanded approx. 2000 bird carcasses recovered from the coastal zone into an

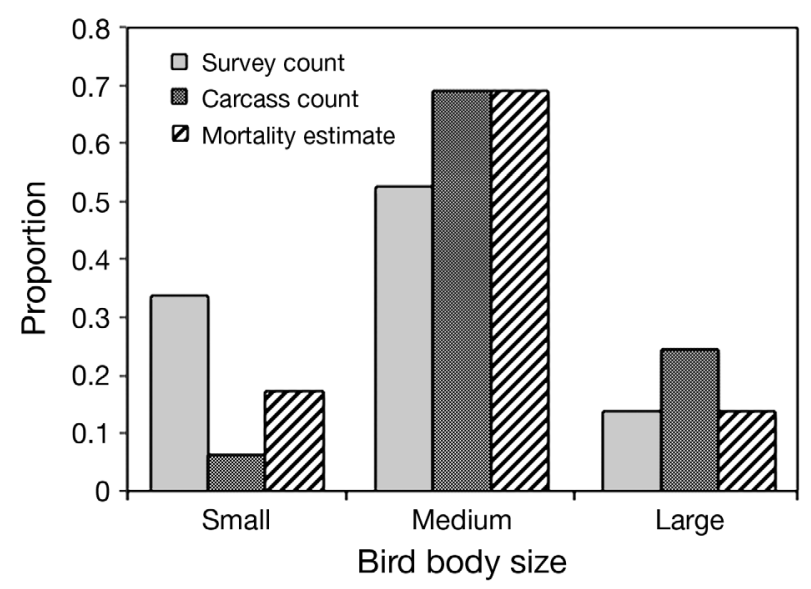

Fig. 3. Comparison of the proportions of birds that were surveyed live in coastal Gulf habitat (Johnson 2011) to the proportions recovered as carcasses and estimated killed during the Deepwater Horizon spill. Bird size categories: small: 10-299 g; medium: 300-499 g; large: $\geq 500 \mathrm{~g}$ estimate of nearly 600000 bird deaths - a very large statistical extrapolation. Even so, those few observed carcasses constitute the actual, observable evidence analyzed in the conventional manner used for avian mortality assessments after oil spills (e.g. Castege et al. 2007, Munilla et al. 2011). What was less conventional was using probability to generate numerical results that include a probability distribution of alternate assumptions about how to statistically expand such carcass counts to account for realistic processes that reduced the numbers recovered from shoreline surveys.

The counts of recovered carcasses are usually far less than the number of birds killed by an oil spill (Seys et al. 2001, Ford 2006). Low carcass counts or small recovery probabilities alone do not necessarily lead to bias. However, in this case, because carcass recovery was low and expansion factors were large, any source of bias would be highly leveraged. For example, if some unmeasured process (e.g. carcass burning) removed even a small number of carcasses en route to shore, each missing carcass would create bias in our estimate proportional to the large expansion factors.

We have tried to understand and account for all recovery processes. On balance we suspect that we were more likely to have underestimated than to have overestimated bird mortality. Nevertheless, if birds tended to fly towards coastlines after exposure, and then later died near or on shore, then we would have underestimated $r$ and overestimated mortality. If the actual decline of seabird density with distance from shore is better described as a negative exponential function, then our assumption of a linear decline also would lead to overestimation of mortality.

Cleanup tactics during spill response may have led to underestimation by intercepting and destroying carcasses before they could be retrieved. Between 28 April and 19 July 2010, 376 controlled burns at sea consumed 3.5 to $4.9 \times 10^{7} 1$ of oil, a volume approximately equivalent to one Exxon Valdez spill. Although burns were avoided if live apex predators were present (Allen et al. 2011), floating carcasses would have been destroyed since ignitions took place where convergences had concentrated buoyant material (FISG 2010). Skimming operations removed half of the oil volume removed by burning (FISG 2010), which may also have removed carcasses.

Carcass loss at sea from biological factors also reduces shoreline deposition. Bird consumption by tiger sharks Galeocerdo cuvier or other higher trophic-level consumers (Kaufman 2012) in the Gulf exacerbates carcass loss (Wiese 2003). Such losses 
lower the estimate of mortality if, as in this study, no correction is applied for in toto ingestion of seabird carcasses.

Our estimate of $5.7 \%$ probability for carcass transport to shorelines is lower than values reported in most previous studies. Piatt \& Ford (1996) reported a probability of $12 \%$. A summary by Munilla et al. (2011) gave a mean of $17.1 \%$ based on 37 experimental studies with 7040 combined block and carcass releases. Block recoveries overstate deposition as blocks do not decompose and weather like carcasses (Wiese \& Jones 2001). Using a block-to-carcass correction provided by Munilla et al. (2011), the difference between values from the meta-analysis above and our study narrows to $11.2 \%$ versus $5.7 \%$, respectively. Our estimate of carcass deposition was nevertheless higher than reported for another Atlantic Ocean oil spill (as low as $0.8 \%$ in the Prestige spill; Castege et al. 2007).

Although we describe the carcass movement with a simple model, the actual movement process was quite complex. Early in the spill, oil was steered away from the coast (Dietrich et al. 2012). Response authorities opened locks on Mississippi River canals to redirect the discharge and prevent or delay Deepwater Horizon oil from reaching the ecologically fragile coastal marshes. Under weak winds and effects of sea surface slope, high buoyancy-driven outflow (Falcini et al. 2012) blocked much of the surface oil from reaching most Gulf shorelines until late May 2010. Except along the immediate shoreline, wind forcing played a negligible role in large-scale oil transport (Huntley et al. 2011) until early July when Tropical Storm Alex transited the southern Gulf (Dietrich et al. 2012, Le Hénaff et al. 2012). Oil was then driven shoreward by the storm surge (Pugliese Carratelli et al. 2011). The extent of oiled shoreline subsequently tripled (Boufadel et al. 2014), and recovery of bird carcasses accelerated just before the well was capped (Belanger et al. 2010).

We assumed that all shorelines affected by this spill were searched (i.e. $h=1.00$ ). Responders searched $6841 \mathrm{~km}$ of the Gulf's beach, wetland, and man-made shorelines during the Deepwater Horizon incident, and some oiling was observed on $1705 \mathrm{~km}$ (Owens et al. 2011a,b). If some shorelines were missed, or if they received less attention by searchers, both of which seem likely given the geographic extent of the Deepwater Horizon spill and the complexity of shorelines, then fewer carcasses would be recovered, ultimately leading to an underestimate of the bird losses.

Our assumed daily carcass persistence proportions of $\sim 50 \%$ on beaches the first few days after deposi- tion is similar to values reported from other oil spills. Nevertheless, as few as $10 \%$ of carcasses may remain 2 to $4 \mathrm{~d}$ after reaching shore (Ford 2006, Byrd et al. 2009, Ford \& Zafonte 2009). Due to the Gulf's many scavengers (e.g. gulls, crows, raptors, raccoons, mink, crabs), shoreline persistence may have been even lower than we assumed. Given search intervals by Deepwater Horizon responders that ranged up to $12 \mathrm{~d}$ (USDOI 2011), our assumed 3 d interval would, at least on some occasions, lead to an overestimate of carcass persistence, ultimately underestimating bird deaths. Carcass persistence was not derived in situ, however, so this parameter had to be approximated from values based on previous oil spills.

\section{Exposure probability model}

Despite a simpler conceptual approach and fewer parameters, the exposure probability model gave an even wider uncertainty interval for the bird deaths estimated in coastal waters (Fig. 2). Here again, we may have made incorrect assumptions about the values of the parameters that led to estimates that erred in either direction.

We assumed that $60 \%$ of coastal birds exposed to Deepwater Horizon oil avoided a lethal dosage. The lethal exposure proportion we used falls near the lower end of the interval of values used to characterize bird mortality from other oil spills (e.g. 23 to $100 \%$; WIW 2001, Robertson et al. 2006, Wilhelm et al. 2007, Fifield et al. 2009). Assuming that warm Gulf waters may be less likely to induce thermoregulatory stress from exposure, we projected that all live oiled birds survived (e.g. see Selman et al. 2012). In cooler seas, live oiled birds are typically included in the tally of mortality (cf. Page et al. 1990, Castege et al. 2007, Munilla et al. 2011). To the extent that we underestimated the lethal dose, we would have underestimated the total bird deaths with the exposure probability approach. We could not, for example, consider all of the ways that oil could lead to mortality, such as via ingestion and inhalation. Any error in Eq. (3) would propagate linearly. If, for example, $60 \%$ of exposed birds died rather than our assumed $40 \%$, then our estimate of total mortality would underestimate by a factor of $60 / 40$ or 1.5 .

We note that few large coastal spills have occurred in warm subtropical seas where the seabird communities comprise high proportions of aerially foraging species. Future study aimed at documenting seabird exposure and behavior around oil slicks in warm oceans are needed (e.g. see Watson et al. 2009). 
Delayed mortality of oiled birds may have occurred at a higher rate than what we assumed.

We can think of several ways we could have overestimated the bird mortality through errors in measurement, incorrect assumptions, or oversimplification. The most obvious potential source for overestimate might be our assumption that the bird density returned to a baseline level of 5.8 birds $\mathrm{km}^{-2}$ due to emigration and bird flux after a period of just $1 \mathrm{~d}$ (but see Fifield et al. 2009). Numbers of birds subject to risk at the time of a spill are often hard to quantify for assessments of spill mortality (e.g. French McCay \& Rowe 2004). The bird density that we used for coastal Gulf waters was typical for seasons when the Deepwater Horizon incident occurred (McFarlane \& Lester 2005), although it was derived from outside the immediate spill zone. We attempted to account for uncertainty in this parameter with an assigned probability distribution, but we have no way to assess our success at estimating the background density or the time it took after mortality for the density to return to the background level because there are no alternative estimates for bird density readily available.

Most importantly, due to limits imposed by image coverage or sensor sensitivity (Leifer et al. 2012, Lindsley \& Long 2012) and high application of chemical dispersants (e.g. Allan et al. 2012), satellite delineation of the exposure risk presented to birds is incomplete (Haney et al. 2014). Underestimation of contamination risk on the water would also lead to underestimation bias in the bird mortality using the exposure probability approach.

\section{Importance of body size}

Our study is among very few to make substantial adjustments to mortality estimation based on carcass size following a large marine oil spill. An adjustment for bird body size was used in the relatively small MV Kure spill $\left(1.7 \times 10^{4} \mathrm{l}\right)$ in Humboldt Bay, California (Ford et al. 2013). Smaller birds are more difficult to detect under field conditions, whether alive (Barbraud \& Thiebot 2009) or dead (Smallwood 2007). Such adjustments are necessary to account for the large disparity observed between relatively low proportions of small bodied carcasses recovered compared with live small birds detected in Gulf surveys (Fig. 3).

Proportionate mortalities from oil spills do vary by body size (Page et al. 1990), although differences among species are not well understood (Evans \&
Keijl 1993). Exposures to very small oil dosages cause loss of plumage integrity (O'Hara \& Morandin 2010), lowering insulation and raising mortality (Jenssen 1994). Because thermal conductance scales allometrically to body size (Aschoff 1981), insulation is more easily compromised in smaller-bodied species, and a greater representation of small birds might be expected in the tally of mortality. Instead, however, only 128 small-bodied carcasses were retrieved during the Deepwater Horizon spill (6.4\% of the total), despite smaller birds making up a third of avian communities in the coastal Gulf (Johnson 2011).

Small-bodied birds may have beach persistence times only 5 to $13 \%$ those of large- and medium-bodied birds (Seys et al. 2001), as small birds are more readily carried off by scavengers (Ford \& Zafonte 2009, Ponce et al. 2010), whereas large, heavy birds must usually be scavenged in situ. In addition, smaller bird carcasses can be scavenged by consumers having a wider range of body sizes, including small-bodied predators. Without correcting for bodysize, especially where bird communities contain a large proportion of small-bodied birds as in the Gulf of Mexico (Johnson 2011), bird losses in marine oil spills could be substantially underestimated.

\section{Ecological implications from spill mortality}

We focused solely on near-term, acute mortality from the Deepwater Horizon spill, even though observations of oiled birds continued for at least $1 \mathrm{yr}$ (Henkel et al. 2012). We did not include estimates for indirect (Velando et al. 2005) or chronic population effects (Irons et al. 2000), either of which can increase the avian mortality (Pérez et al. 2008). For example, oil cleanup and other response activities reduce bird survival (Burger \& Tsipoura 1998).

Despite a focus here on near-term effects, high avian mortality in the Deepwater Horizon spill likely had population-level repercussions. We estimated mortality in 4 seabird species using the size-specific expansion factors $\left(1 / p_{j}\right.$ listed in Table 2$)$ and numbers of carcasses found for that species (listed in Supplement 1). Projected losses reached or exceeded 24000 birds in all 4 species and reached 232000 for laughing gulls (Leucophaeus atricilla, Table 3). In 3 species, estimated losses reached or exceeded $12 \%$ of the total population estimated present in the northern Gulf of Mexico.

Mortality of laughing gulls was $\sim 32 \%$ of the regional Gulf population (Table 3). National Audubon Society Christmas Bird Count (CBC) data from Florida, Ala- 
Conf Proc, Vol 2011, No. 1, American Petroleum Institute, Washington DC

Antonio FJ, Mendes RS, Thomaz SM (2011) Identifying and modeling patterns of tetrapod vertebrate mortality rates in the Gulf of Mexico oil spill. Aquat Toxicol 105:177-179

- Aschoff J (1981) Thermal conductance in mammals and birds: its dependence on body size and circadian phase. Comp Biochem Physiol 69:611-619

- Balseiro A, Espí A, Márquez I, Pérez V, Ferreras MC, García Marín JF, Prieto JM (2005) Pathological features in marine birds affected by the Prestige's oil spill in the north of Spain. J Wildl Dis 41:371-378

Barbraud C, Thiebot JB (2009) On the importance of estimating detection probabilities from at-sea surveys of flying seabirds. J Avian Biol 40:584-590

Barker CH (2011) A statistical outlook for the Deepwater Horizon oil spill. In: Liu Y, MacFadyen A, Ji ZG, Weisberg RH (eds) Monitoring and modeling the Deepwater Horizon oil spill: a record-breaking enterprise. Geophys Monogr Ser 195. American Geophysical Union, Washington, DC, p 237-244

Belanger M, Tan L, Askin N, Wittnich C (2010) Chronologic effects of the Deepwater Horizon Gulf of Mexico oil spill on regional seabird casualties. J Mar Anim Ecol 3:10-14

Belant JL, Dolbeer RA (1993a) Population status of nesting laughing gulls in the United States, 1977-1991. Am Birds 47:220-224

Belant JL, Dolbeer RA (1993b) Migration and dispersal of laughing gulls in the United States. J Field Ornithol 64: 557-565

Boufadel MC, Abdollahi-Nasab A, Geng X, Galt J, Torlapati J (2014) Simulation of the landfall of the Deepwater Horizon oil on the shorelines of the Gulf of Mexico. Environ Sci Technol 48:9496-9505

Briggs KT, Yoshida SH, Gershwin ME (1996) The influence of petrochemicals and stress on the immune system of seabirds. Regul Toxicol Pharmacol 23:145-155

Buckley PA, Buckley FG (2002) Royal tern (Thalasseus maximus). In: Poole A (ed) The birds of North America online. Cornell Lab of Ornithology, Ithaca, New York. (http://bna.birds.cornell.edu/bna/species/700; accessed 9 June 2013)

Burger J (1996) Laughing gull (Leucophaeus atricilla). In: Poole A (ed) The birds of North America online. Cornell Lab of Ornithology, Ithaca, New York. (http://bna.birds. cornell.edu/bna/species/225; accessed 9 June 2013)

Burger J, Tsipoura N (1998) Experimental oiling of sanderlings (Calidris alba): behavior and weight changes. Environ Toxicol Chem 17:1154-1158

Byrd GV, Reynolds JH, Flint PL (2009) Persistence rates and detection probabilities of bird carcasses on beaches of Unalaska Island, Alaska, following the wreck of the M/V Selendang Ayu. Mar Ornithol 37:197-204

> Camilli R, Di Iorio D, Bowen A, Reddy CM and others (2012) Acoustic measurement of the Deepwater Horizon Macondo well flow rate. Proc Natl Acad Sci USA 109: 20235-20239

> Camphuysen CJ, Heubeck M (2001) Marine oil pollution and beached bird surveys: the development of a sensitive monitoring instrument. Environ Pollut 112:443-461

Casella G, Berger RL (2002) Statistical inference, 2nd edn. Wadsworth and Brooks/Cole, Pacific Grove, CA

Castege I, Lalanne Y, Gouriou V, Hemery G and others (2007) Estimating actual seabirds mortality at sea and relationship with oil spills: lessons from the Prestige oil spill in Aquitaine (France). Ardeola 54:289-307

> Chardine JW, Rail JF, Wilhelm S (2013) Population dyna- mics of northern gannets in North America, 1984-2009. J Field Ornithol 84:187-192

Clarke ED, Spear LB, McCracken ML, Marques FCC, Borchers DL, Buckland ST, Ainley DG (2003) Validating the use of generalized additive models and at-sea surveys to estimate size and temporal trends of seabird populations. J Appl Ecol 40:278-292

> Dietrich JC, Trahan CJ, Howard MT, Fleming JG and others (2012) Surface trajectories of oil transport along the northern coastline of the Gulf of Mexico. Cont Shelf Res 41:17-47

Dolbeer RA, Bernhardt GE (2003) Age-specific reproduction in female laughing gulls (Larus atricilla). Auk 120: 531-535

Evans MI, Keijl GO (1993) Impact of Gulf War oil spills on the wader populations of the Saudi Arabian Gulf coast. Sandgrouse 15:85-105

- Falcini F, Jerolmack DJ, Buongiorno Nardelli B (2012) Mississippi River and sea surface height effects on oil slick migration. PLoS ONE 7:e36037

Fifield DA, Baker KD, Byrne R, Robertson GJ and others (2009) Modelling seabird oil spill mortality using flight and swim behaviour. Environ Studies Res Funds Rep 186, Canadian Wildlife Service, Dartmouth, NS

FISG (Federal Interagency Solutions Group) (2010) Oil budget calculator, Deepwater Horizon: a report to the National Incident Command. Tech Doc Oil Budget Science \& Engineering Team (http://www.restorethegulf.gov/sites/ default/files/documents/pdf/OilBudgetCalc_Full_HQPrint_111110.pdf; accessed 17 Sep 2014)

Ford RG (2006) Using beached bird monitoring data for seabird damage assessment: the importance of search interval. Mar Ornithol 34:91-98

Ford RG, Zafonte MA (2009) Scavenging of seabird carcasses at oil spill sites in California and Oregon. Mar Ornithol 37:205-211

Ford RG, Casey JL, Hewitt CH, Lewis DB, Varoujean DH, Warrick DR, Williams WA (1991) Seabird mortality resulting from the Nestucca oil spill incident, winter 1988-89. Report for Washington Department of Wildlife. Ecological Consulting, Portland, OR

Ford RG, Sharp BE, Zafonte M (2013) The efficiency of searchers recovering seabirds and waterfowl killed in the 1997 M/V Kure oil spill in northern California. California Dept of Fish \& Game, Sacramento, CA (https:// nrm.dfg.ca.gov/FileHandler.ashx? DocumentID=20097; accessed 8 Apr 2013)

French McCay D, Rowe JJ (2004) Evaluation of bird impacts on historical oil spill cases using the SIMAP oil spill model. In: Proc 27th Arct Mar Oil Spill Program (AMOP) Tech Semin, Ottawa, p 421-452

> Garcia-Pineda O, MacDonald IR, Li X, Jackson CR, Pichel WG (2013) Oil spill mapping and measurement in the Gulf of Mexico with textural classifier neural network algorithm (TCNNA). IEEE J Selected Topics Appl Earth Observ Remote Sens 6:2517-2525

> Haney JC, Geiger HJ, Short JW (2014) Bird mortality from the Deepwater Horizon oil spill. I. Exposure probability in the offshore Gulf of Mexico. Mar Ecol Prog Ser 513: 225-237

> Henkel JR, Sigel BJ, Taylor CM (2012) Large-scale impacts of the Deepwater Horizon oil spill: can local disturbance affect distant ecosystems through migratory shorebirds? Bioscience 62:676-685

Hess NA, Ribic CA (2000) Seabird ecology. In: Davis RW, Evans WE, Würsig B (eds) Cetaceans, sea turtles and seabirds in the northern Gulf of Mexico: distribution, 
abundance and habitat associations. Vol II: Technical Report. Prepared by Texas A\&M University, Galveston, TX; and National Marine Fisheries Service, New Orleans, LA. OCS Study MMS 2000-003, p 275-316

Huntley HS, Lipphardt BL, Kirwan AD (2011) Surface drift predictions of the Deepwater Horizon spill: the Lagrangian perspective. In: Liu Y, MacFadyen A, Ji ZG, Weisberg RH (eds) Monitoring and modeling the Deepwater Horizon oil spill: a record-breaking enterprise. Geophys Monogr Ser 195. American Geophysical Union, Washington, DC, p 179-195

Irons DB, Kendall SJ, Erickson WP, McDonald LL, Lance BK (2000) Nine years after the Exxon Valdez oil spill: effects on marine bird populations in Prince William Sound, Alaska. Condor 102:723-737

> Jenssen BM (1994) Review article: effects of oil pollution, chemically treated oil, and cleaning on thermal balance of birds. Environ Pollut 86:207-215

Johnson EI (2011) Audubon coastal bird survey: first annual report, July 2011. National Audubon Society, Baton Rouge, LA

Kaufman R (2012) Sharks eating songbirds in Gulf of Mexico (http://news.nationalgeographic.com/news/2012/01/ 120113-sharks-songbirds-gulf-of-mexico-animals-fishscience/; accessed 27 Feb 2013)

Le Hénaff M, Kourafalou VH, Paris CB, Helgers J, Aman ZM, Hogan PJ, Srinivasan A (2012) Surface evolution of the Deepwater Horizon oil spill patch: combined effects of circulation and wind-induced drift. Environ Sci Technol 46:7267-7273

Leifer I, Lehr WJ, Simecek-Beatty D, Bradley E and others (2012) State of the art satellite and airborn marine oil spill remote sensing: application to the BP Deepwater Horizon oil spill. Remote Sens Environ 124:185-209

Leighton FA (1993) The toxicity of petroleum oils to birds. Environ Rev 1:92-103

Lindsley RD, Long DG (2012) Mapping surface oil extent from the Deepwater Horizon oil spill using ASCAT backscatter. IEEE Trans Geosci Rem Sens 50: 2534-2541

MacFadyen A, Watabayashi GY, Barker CH, Beegle-Krause CJ (2011) Tactical modeling of surface oil transport during the Deepwater Horizon spill response. In: Liu Y, MacFadyen A, Ji ZG, Weisberg RH (eds) Monitoring and modeling the Deepwater Horizon oil spill: a recordbreaking enterprise. Geophys Monogr Ser 195. American Geophysical Union, Washington, DC, p 167-178

McFarlane RW, Lester LJ (2005) Determination of nearshore seabird density on the upper Texas coast. Final report. State Energy Conservation Office, Austin, TX (www. seco.cpa.state.tx.us/re/docs/re_wind_projects-bird.pdf; accessed 22 Feb 2013)

McNutt MK, Camilli R, Crone TJ, Guthrie GD and others (2012) Review of flow rate estimates of the Deepwater Horizon oil spill. Proc Natl Acad Sci USA 109: 20260-20267

Michel J, Owens EH, Zengel S, Graham A and others (2013) Extent and degree of shoreline oiling: Deepwater Horizon oil spill, Gulf of Mexico, USA. PLoS ONE 8:e65087

Montevecchi W, Fifield D, Burke C, Garthe S, Hedd A, Rail JF, Robertson G (2012) Tracking long-distance migration to assess marine pollution impact. Biol Lett 8:218-221

Mowbray TB (2002) Northern gannet (Morus bassanus). In: Poole A (ed) The birds of North America online. Cornell Lab of Ornithology, Ithaca, NY (http://bna.birds.cornell. edu/bna/species/693; accessed 9 June 2013)

Munilla I, Arcos JM, Oro D, Álvarez D, Leyenda PM, Ve- lando A (2011) Mass mortality of seabirds in the aftermath of the Prestige oil spill. Ecosphere 2:art83

NAS (National Audubon Society) (2010) The Christmas bird count historical results [Online] (http://netapp.audubon. org/CBCObservation/Historical/ResultsBySpecies.aspx?1; accessed 12 Sep 2013)

Nelson B (1979) Seabirds: their biology and ecology. A\&W Publishers, New York, NY

Norse EA, Amos J (2010) Impacts, perception, and policy implications of the Deepwater Horizon oil and gas disaster. Environ Law Report 40:11058-11073

O'Hara PD, Morandin LA (2010) Effects of sheens associated with offshore oil and gas development on the feather microstructure of pelagic seabirds. Mar Pollut Bull 60: 672-678

> Oppel S, Meirinho A, Ramirez I, Gardner B, O'Connell A, Louzao M (2012) Comparison of five modelling techniques to predict the spatial distribution and abundance of seabirds. Biol Conserv 156:94-194

Owens E, Taylor E, Michel J (2011a) The Deepwater Horizon-Macondo 2010 Shoreline Cleanup Assessment Technique (SCAT) program. GSA Abstracts with Programs 43:11

Owens EH, Santner R, Cocklan-Vendl M, Michel J, Reimer PD, Stong B (2011b) Shoreline treatment during the Deepwater Horizon-Macondo response. Int Oil Spill Conf 271:1-9

Page GW, Carter HR, Ford RG (1990) Numbers of seabirds killed or debilitated by the 1986 Apex Houston oil spill in central California. Stud Avian Biol 14:164-174

Peake DE (1996) Bird surveys. In: Davis RW, Fargion GS (eds) Distribution and abundance of cetaceans in the north-central and western Gulf of Mexico, Vol II. Technical Report, OCS Study MMS 96-0027. US Department of the Interior, New Orleans, LA, p 271-304

> Pérez C, Velando A, Munilla I, López-Alonso M, Oro D (2008) Monitoring polycyclic aromatic hydrocarbon pollution in the marine environment after the Prestige oil spill by means of seabird blood analysis. Environ Sci Technol 42:707-713

Peterson CH (2001) The 'Exxon Valdez' oil spill in Alaska: acute, indirect and chronic effects on the ecosystem. Adv Mar Biol 39:1-103

Peterson CH, Anderson SS, Cherr GN, Ambrose RF and others (2012) A tale of two spills: novel science and policy implications of an emerging new oil spill model. Bioscience 62:461-469

Piatt JF, Ford RG (1996) How many seabirds were killed by the Exxon Valdez oil spill? Proc Exxon Valdez Oil Spill Symp, Anchorage, AK. Am Fish Soc Symp 18:712-719

Ponce C, Alonso JC, Argandoña G, García Fernández A, Carrasco M (2010) Carcass removal by scavengers and search accuracy affect bird mortality estimates at power lines. Anim Conserv 13:603-612

Poulain PM, Gerin R, Mauri E (2009) Wind effects on drogued and undrogued drifters in the Eastern Mediterranean. J Atmos Ocean Technol 26:1144-1156

Pugliese Carratelli E, Dentale F, Reale F (2011) On the effects of wave-induced drift and dispersion in the Deepwater Horizon oil spill. In: Liu Y, MacFadyen A, Ji ZG, Weisberg RH (eds) Monitoring and modeling the Deepwater Horizon oil spill: a record-breaking enterprise. Geophys Monogr Ser 195. American Geophysical Union, Washington, DC, p 197-204

Rattiste K (2004) Reproductive success in presenescent common gulls (Larus canus): the importance of the last year of life. Proc R Soc Lond Ser B Biol Sci 271:2059-2064 
Robertson GJ, Ryan PC, Dussureault J, Turner BC, Wilhelm SI, Power K (2006) Composition of beached marine birds from an oiling event in southeastern Newfoundland and Labrador, November 2004. Mar Ornithol 34:141-146

Selman W, Hess TJ, Salyers B, Salyers C (2012) Short-term response of brown pelicans (Pelecanus occidentalis) to oil spill rehabilitation and translocation. Southeast Nat 11:G1-G16

Seys J, Offringa H, Van Waeyenberge J, Meire P, Kuijken E (2001) Numbers of beached bird corpses and mortality of seabirds, how do they relate: a North Sea study in a wider context. In: Seys J (author) Het gebruik van zeeen kustvogelgegevens ter ondersteuning van het beleid en beheer van de Belgische kustwateren. PhD thesis, Universiteit Gent, p 78-96

Shields M (2002) Brown pelican (Pelecanus occidentalis). In: Poole A (ed) The birds of North America online. Cornell Lab of Ornithology, Ithaca, NY (http://bna.birds.cornell. edu/bna/species/609; accessed 16 June 2013)

Silver N (2012) The signal and the noise: why so many predictions fail-but some don't. Penguin Press, New York, NY

Smallwood KS (2007) Estimating wind turbine-caused bird mortality. J Wildl Manag 71:2781-2791

Stienen EWM, Haelters J, Kerckhof F, Van Waeyenberge J (2004) Three colours of black: seabird strandings in Belgium during the Tricolor incident. Atlas Seab 6: 129-146

Tan L, Belanger M, Wittnich C (2008) Revising the correlation between estimated seabird mortality and oil spill size. J Mar Anim Ecol 3:20-26

Thompson SK (2002) Sampling, 2nd edn. Wiley, New York, NY

USDOI (United States Department of Interior) (2011) Work plan (bird study \#1C): beached carcass persistence study. Final report, 7 June 2011 (www.doi.gov/deepwaterhorizon/ adminrecord/upload/BIRD_Telemetry_Carcass_Drift_

Editorial responsibility: Jacob González-Solís, Barcelona, Spain
1D_corrected-signature-page-final-executed-plan.pdf; accessed 10 March 2013)

Van Pelt TI, Piatt JF (1995) Deposition and persistence of beachcast seabird carcasses. Mar Pollut Bull 30:794-802

Velando A, Munilla I, Leyenda PM (2005) Short-term indirect effects of the 'Prestige' oil spill on European shags: changes in availability of prey. Mar Ecol Prog Ser 302: 263-274

> Votier SC, Birkhead TR, Oro D, Trinder M and others (2008) Recruitment and survival of immature seabirds in relation to oil spills and climate variability. J Anim Ecol 77: 974-983

Watson JEM, Joseph LN, Watson AWT (2009) A rapid assessment of the impacts of the Montara oil leak on birds, cetaceans and marine reptiles. Report to Dept Environment, Water, Heritage and Arts, Canberra (www. environment.gov.au/coasts/publications/pubs/montararapid-survey.pdf; accessed 12 Sep 2013)

Wiese FK (2003) Sinking rates of dead birds: improving estimates of seabird mortality due to oiling. Mar Ornithol 31: $65-70$

- Wiese FK, Jones IL (2001) Experimental support for a new drift block design to assess seabird mortality from oil pollution. Auk 118:1062-1068

> Wiese FK, Robertson GJ (2004) Assessing seabird mortality from chronic oil discharges at sea. J Wildl Manag 68: 627-638

Wilhelm SI, Robertson GJ, Ryan PC, Schneider DC (2007) Comparing an estimate of seabirds at risk to a mortality estimate from the November 2004 Terra Nova FPSO oil spill. Mar Pollut Bull 54:537-544

WIW (Wildlife Injury Workgroup) (2001) Estimate of total acute mortality to birds resulting from the Chalk Point oil spill, Swanson Creek, Maryland, April 7, 2000. Final report. NOAA, Silver Springs, MD (www.darrp.noaa. gov/northeast/chalk_point/pdf/cp2048.pdf; accessed 8 March 2013)

Submitted: October 16, 2013; Accepted: April 30, 2014

Proofs received from author(s): September 30, 2014 